соискатель кафедры социологии управления факультета государственного управления Московского государственного университета имени М.В. Ломоносова

\section{ТРАНСФОРМАЦИЯ ТРУДОВЫХ ОТНОШЕНИЙ В УСЛОВИЯХ ИНФОРМАТИЗАЦИИ}

Аннотация:

В статье рассмотрены социальные аспекты развития дистанционных трудовых отношений. Отмечены причины широкого распространения дистанционной занятости с применением информационнокоммуникационных технологий, среди которых стремление к оптимизации трудовых процессов, гибкость графика работы, повышение мобильности специалистов, возможность привлечения высококвалифицированных кадров и др. Охарактеризованы особенности социально-экономических отношений на рынке дистанционного труда. Представлены данные Международной организации труда по дистанционной занятости в развитых странах. Обозначено, что в России дистанционная форма трудовой занятости с применением ИКТ используется в создании объектов интеллектуальной собственности. Установлено, что для построения модели культуры дистанционных трудовых отношений следует применять наработки в области социологии управления, информационных технологий, а также подходы других наук, в рамках которых исследуется сфера труда.

Ключевые слова:

дистанционная занятость, удаленная работа, дuстанционный работник, социальные отношения, культура социального управления, дистанционный труд, фриланс.
PhD applicant Sociology of Management Department, School of Public Administration, Lomonosov Moscow State University

\section{THE TRANSFORMATION OF LABOUR RELATIONS IN THE CONTEXT OF INFORMATIZATION}

\begin{abstract}
Summary:
The paper examines the social aspects of the remote labour relations development. The study notes the reasons for a widespread remote employment via information and communication technologies that are to optimize workflow, provide flexible working hours, en hance employees' mobility, and involve qualified staff. The features of social and economic relations on the remote labour market are described. The research presents the teleworking data in the developed countries provided by the International Labour Organization. It is noted that telework in Russia based on the ICTs is applicable for intellectual property. To build a culture model for remote labour relations, one should apply the practices of the sociology of management, information technologies and the approaches of other sciences to studying the labour environment.
\end{abstract}

Keywords: remote employment, remote work, remote employee, social relations, culture of social management, teleworking, freelance.

Широкое проникновение информационно-коммуникационных технологий (ИКТ) во все сферы жизнедеятельности общества заставляет людей ориентироваться в новых реалиях для осуществления более эффективного выбора. Главным образом это затрагивает сферу труда, в частности занятости населения. С помощью информационных технологий стали возможными коммуникации внутри и между фрирмами в мировом масштабе. Согласно исследованию, проведенному компанией Symantec в 2009-2011 гг., число сотрудников, работающих удаленно, значительно возросло и продолжает расти. В 2009 г. в мире работали дистанционно 22 \% работников, в 2012 г. - 32 \% [1], а уже в 2015 г., согласно докладу Международной организации труда (MOT) о возможностях и проблемах, связанных с ростом масштабов удаленной работы, доля занятых удаленно варьируется до 40 \% (в зависимости от страны) [2].

Теперь специалистам не обязательно физически присутствовать на рабочем месте. Процесс работы может происходить не только на территории нанимателя, результат работы может быть передан последнему в любом месте. Сильна тенденция к работе в режиме онлайн, когда наниматель и нанимаемое лицо, находясь в различных местах, поддерживают рабочий контакт с помощью информационных технологий. Данные характеристики становятся все более весомыми в информационном веке.

Впервые термин «дистанционный труд» был предложен в 1972 г. американцем Дж. Найллзом для обозначения дистанционной работы по договору. В 2012 г. в статье авторитетного американского электронного издания BizTech «Отцы технологий: 10 людей, которые изобрели инновации в области технологий» [3] Найллз назван одной из самых выдающихся личностей в области инновационных технологий. Распространение дистанционной формы занятости является основной тенденцией в развитии социально-трудовых отношений. 
Все более широкое применение нетипичных форм занятости обусловлено рядом негативных экономических и социальных факторов и вместе с тем обладает определенными преимуществами. В российской науке происходит процесс формирования и выработки единого подхода к пониманию дистанционных трудовых отношений, связанных с дистанционной занятостью.

Основными причинами широкого распространения дистанционной занятости с применением ИКТ являются:

- стремление к оптимизации трудовых процессов,

- гибкость графика работы и повышение мобильности,

- создание рабочих мест,

- улучшение соотношения работы и личной жизни,

- возможность привлечения высококвалифицированных кадров.

В условиях сервисной экономики через глобальную сеть могут работать профессионалы в любой области: программисты, дизайнеры, художники, редакторы, переводчики, писатели, финансисты, юристы, медики, архитекторы, т. е. те специалисты, продукт деятельности которых можно доставить к заказчику с помощью ИКТ (сети Интернет).

В развитых странах, согласно докладу МОТ, опубликованному в 2017 г., доля работающих удаленно составляет 17 \%, в США и Японии - почти 37 и 32 \% соответственно. В Европейском союзе около 10 \% сотрудников в 2015-2016 гг. время от времени работали удаленно, вне привязки к офису работали 5 \%, а 3 \% работников ежедневно выполняли удаленную работу из дома [4]. В России, стране с богатым интеллектуальным потенциалом, дистанционная фрорма трудовой занятости с применением ИКТ используется в создании объектов интеллектуальной собственности.

В период активного перемещения экономической деятельности в виртуальное пространство наблюдается тенденция, когда фрирмы расположены в экономически развитых государствах, а персонал, осуществляющий основную деятельность, посредством ИКТ нанимается в тех странах, где стоимость трудовых ресурсов для этого вида деятельности низкая.

Многие современные авторы рассматривают дистанционную занятость преимущественно с точки зрения экономического подхода, т. е. как часть экономических отношений. Рациональному развитию дистанционных трудовых отношений способствует социокультурный подход. Л.И. Уварова отмечает важность такого подхода в решении проблем общественного развития. В одной из своих статей Л.И. Уварова утверждает следующее: «Социокультурный подход... отражает наметившуюся смену самой парадигмы цивилизационного развития: переход от свойственного индустриальному обществу технократизма к культуроцентризму, на котором будет основываться грядущая цивилизация постматериальных ценностей» [5, с. 54].

Общество представляет собой сложную динамическую систему связи людей, объединенных семейными, групповыми, сословными, классовыми отношениями [6]. Глобальные проблемы выживания человеческого рода становятся определяющими для нормального общественного развития, что подразумевает существование общественных отношений.

Философский энциклопедический словарь определяет отношения как «взаимозависимость элементов определенной системы. Отношения вещей и явлений друг к другу бесконечно многообразны: пространственные и временные, причинно-следственные, части и целого, фрормы и содержания. Особый тип представляют общественные отношения» [7].

Основателем психологической теории отношений в России является А.Ф. Лазурский (18741917). Им была выдвинута концепция отношений личности, развитая впоследствии его учеником, видным советским психологом В.Н. Мясищевым, который видел сущность отношения в том, что «оно является одной из форм отражения человеком окружающей его действительности. Формирование отношений в структуре личности человека происходит в результате отражения им на сознательном уровне сущности тех социальных объективно существующих отношений общества в условиях его макро- и микробытия, в котором он живет». По мнению В.Н. Мясищева, отношения личности - ее интересы, потребности, склонности - являются прежде всего результатом того, как человеку удается взаимодействовать с совершенно конкретной для него окружающей средой и насколько эта среда дает простор для проявления и развития его индивидуальности и в предметной деятельности, и при взаимодействии с другими людьми [8].

По мнению М. Вебера, признаком социального отношения служит степень отношения одного индивида к другому. Содержанием социального отношения могут быть «борьба, вражда, любовь, дружба, уважение, рыночный обмен, “выполнение” соглашения, "уклонение" или отказ от него, соперничество экономического, эротического или какого-либо иного характера; сословная, национальная или классовая общность...» [9, с. 630].

Таким образом, общество представляет собой социальную сущность, социальные общности, деятельность, взаимосвязи, т. е. социальные отношения, в которых люди выполняют определенные социальные роли. В рамках общества всегда имеет место социальное взаимодействие. Социальные отношения, вытекающие из этого взаимодействия, различны по качеству и интенсивности, зависят от личностных качеств взаимодействующих индивидов. 
А.В. Чичканов под социальными отношениями подразумевает один из основных типов общественных отношений, проявляющихся в крупной, относительно самостоятельной и устойчивой части общества - в его социальной сфере. К ней относятся все субъекты и процессы, принимающие прямое, непосредственное участие в формировании свойств системы, связанных с воспроизводством и совершенствованием личности (группы), удовлетворением ее витальных и высших потребностей [10, с. 10].

Иначе говоря, социальные отношения могут охватывать большой диапазон социальных систем, содержащих обязательные элементы: субъекты взаимодействия, связующее их звено, систему функций, обязательных к выполнению относительно других субъектов взаимодействия.

Социальные отношения тесно связаны и обусловлены трудовыми отношениями. В условиях глобализации интенсивно меняются обустройство мира, характер и отношение к труду, характер рабочей силы и связанные с ними трудовые отношения. Социально-трудовые отношения дают возможность установить и определить социальную роль, общественное положение отдельного индивида и социальной общности в целом. Сфера труда и существующие в ней социальнотрудовые отношения являются одной из главных составляющих общественной жизни.

Трудовой рынок представляет собой систему общественных отношений, которые отражают степень развития и достигнутое на данный момент соотношение интересов между присутствующими на рынке субъектами: работодателями, наемными работниками и государством. Таким образом, социально-экономические отношения на рынке труда складываются из трех главных компонентов:

1) отношения между работодателями (предпринимателями) и трудящимися (наемными работниками);

2) отношения между субъектами рынка труда и их представителями (службами занятости, ассоциациями, профсоюзами);

3) отношения между работодателями, трудящимися и государством.

Работодатели - субъекты социально-трудовых отношений - люди, работающие самостоятельно и нанимающие на работу одного и более человек.

Наемные работники - самая многочисленная часть субъектов рынка труда. Наемный работник - фризическое лицо, заключившее трудовой договор с работодателем. К ним относятся люди, живущие за счет продажи своих способностей к труду - рабочей силы. Их уровень материального обеспечения напрямую зависит от того, насколько успешно они могут продать свою рабочую силу - заключить трудовой договор и получить работу.

«Государство как субъект социально-трудовых отношений выполняет законодательную, регулирующую функции. Государственную политику в связи с рынком труда следует понимать как совокупность социально-экономических мер, принимаемых государством для достижения поставленных целей в сфере воспроизводства (улучшение профессионального состава и других структурных характеристик), обмена (предложение рабочих мест, совершенствование механизмов трудоустройства и социальной поддержки ищущих работу, ведения переговоров, заключения контрактов) и использования рабочей силы (стимулирование роста производительности труда, регулирование оплаты труда, условий труда, урегулирование конфликтов)» [11, с. 21].

Работник и работодатель имеют противоположные интересы, в связи с чем трудовое отношение является по своей социально-экономической природе противоречивым. Поэтому важным условием для возникновения трудовых отношений является юридическая независимость равноправных субъектов.

С точки зрения управления дистанционными трудовыми отношениями сфера труда представляет особый интерес как основа социальных отношений. М.Г. Либо и С.В. Кошелева отмечают, что «феномен удаленной работы проявляется на пересечении двух важнейших областей современного менеджмента: человеческих ресурсов и информационных технологий» $[12$, с. 117].

Более того, сфера труда как поле исследования охватывает множество проблемных вопросов, являющихся предметом изучения разных наук: социологии управления, информационных технологий и права. Для построения модели культуры дистанционных трудовых отношений нельзя ограничиться отдельными наработками в сфере социологии управления, равно как и нельзя в отдельности применить знания в области информационных технологий.

По мере развития информационных технологий увеличивается число дистанционных работников. Дистанционные трудовые отношения позволяют работодателю привлекать профессионалов из регионов, тем самым оптимизируя бюджет и улучшая качество выполняемых работ, а работнику - трудоустройство даже из региона с высоким уровнем безработицы.

\section{Ссылки:}

1. Катенева Ю. Удаленных работников хотят уравнять с офисными [Электронный ресурс] // Профсоюзы сегодня: профрсоюзный информационный портал. URL: http://www.unionstoday.ru/news/russian/2012/10/05/17278 (дата обращения: 20.11.2017) 
2. Working Anytime, Anywhere: The Effects on the World of Work : joint Eurofound and International Labour Office report / J. Messenger, [etc.]. 2017. https://doi.org/10.2806/425484.

3. Ribeiro R. Fathers of Technology: 10 Men Who Invented and Innovated in Tech [Электронный ресурс] // Biztech. 2012. URL: http://www.biztechmagazine.com/article/2012/06/fathers-technology-10-men-who-invented-and-innovated-tech (дата обращения: 01.12.2017).

4. Working Anytime, Anywhere ...

5. Уварова Л.И. Формирование культуры управления в процессе профессионального образования: социокультурный подход // Вопросы культурологии. 2008. № 11. С. 54-57.

6. Общая теория права и государства : учеб. для вузов / под ред. В.В. Лазарева. Изд. 3-е, перераб. и доп. М., 2001.

7. Философский энциклопедический словарь / гл. ред.: Л.Ф. Ильичев, П.Н. Федосеев, С.М. Ковалев, В.Г. Панов. М., 1983.

8. Мясищев В.Н. Психология отношений. М., 1995.

9. Вебер М. Избранные произведения : пер. с нем. / сост., общ. ред. и послесл. Ю.Н. Давыдова ; предисл. П.П. Гайденко. M., 1990.

10. Чичканов А.В. Социальные отношения в современном российском обществе (социологический анализ) : автореф. дис. ... д-ра социол. наук. М., 2008.

11. Кашепов А.В., Сулакшин С.С., Малчинов А.С. Рынок труда: проблемы и решения : монография. М., 2008. 232 с.

12. Либо М.Г., Кошелева С.В. Телеработа как новая форма управления персоналом в организациях виртуального типа // Вестник Санкт-Петербургского университета. Менеджмент. Серия 8. 2004. № 3 (24). С. 117-137.

\section{References:}

Chichkanov, AV 2008, Social relations in modern Russian society (sociological analysis), D.Phil. thesis abstract, Moscow, (in Russian).

llyichev, LF, Fedoseev, PN, Kovalev, SM \& Panov, VG 1983, Philosophical encyclopaedic dictionary, Moscow, (in Russian). Kashepov, AV, Sulakshin, SS \& Malchinov, AS 2008, Labor market: problems and solutions, monograph, Moscow, 232 p., (in Russian).

Kateneva, Yu 2017, 'Remote and office employees are to be equalized', Profsoyuzy segodnya: profsoyuznyy informatsionnyy portal, viewed 20 November 2017, <http://www.unionstoday.ru/news/russian/2012/10/05/17278>, (in Russian).

Lazarev, VV (ed.) 2001, General theory of law and state, textbook, 3rd ed., Moscow, (in Russian).

Libo, MG \& Kosheleva, SV, 'Teleworking as a new form of personnel management in virtual organizations', Vestnik SanktPeterburgskogo universiteta. Menedzhment, Series 8, no. 3 (24), pp. 117-137, (in Russian). Messenger, J (et al.) 2017, Working Anytime, Anywhere: The Effects on the World of Work: joint Eurofound and International Labour Office report. https://doi.org/10.2806/425484.

Myasishchev, VN 1995, Psychology of relations, Moscow, (in Russian).

Ribeiro, R 2012, 'Fathers of Technology: 10 Men Who Invented and Innovated in Tech', Biztech, viewed 01 December 2017 , $<$ http://www.biztechmagazine.com/article/2012/06/fathers-technology-10-men-who-invented-and-innovated-tech>.

Uvarova, LI 2008, 'Development of management culture in the process of professional education: social and cultural approach', Voprosy kul'turologii, no. 11, pp. 54-57, (in Russian).

Weber, M, Davydov, YuN \& Gaidenko, PP 1990, Selected works, Moscow, (in Russian). 